\title{
A Review of Some Significant Research Trends in Thermophysiological Comfort of Fabrics to Suit Varied Areas of Applications and Weather Conditions
}

\author{
Kavitha $\mathrm{S}^{1 *}$ and Gokarneshan $\mathrm{N}^{2}$ \\ ${ }^{1}$ Department of Fashion Technology, Kumaraguru College of technology, India \\ ${ }^{2}$ Department of Textile Technology, Bannariamman Institute of Technology, India
}

Submission: November 12, 2019; Published: December 11, 2019

*Corresponding author: Kavitha S, Department of Fashion Technology, Kumaraguru College of technology, India

\begin{abstract}
The article critically reviews some significant trends attempted in enhancing the thermal comfort of fabrics. One attempt has been directed towards providing protective clothing for workers in harsh weather conditions of extreme cold climate. It aimed to determine how the people working in cold harsh climatic regions protect themselves against cold and the sufficiency, and the selection criteria of the garments. Basic thermal insulation of the reported clothing has been estimated. The thermal insulation of the clothing have been measured by thermal manikin(standing/walking). It has been found that the thermal insulation of the selected clothing was on an average 1.2 and 1.5 in mild cold (-5 to $\left.+5^{\circ} \mathrm{C}\right)$ and dry cold $\left(-20\right.$ to $\left.-10^{\circ} \mathrm{C}\right)$ conditions, respectively. The findings revealed that workers selected their clothing based on occupational (time outdoors), environmental (temperature, wind, moisture) and individual (cold sensitivity, general health). A special design of clothing based on 'sombero-effect' by inclined wedge providing shadow on the base material has been proposed and investigated analytically to improve the thermophysiological comfort under dry and hot environment. The analysis of the heat and mass transfer in the proposed design enables numerical prediction of cooling heat flow at skin surface level. It is observed that the analytical framework of heat and mass transfer is able to give useful results.
\end{abstract}

A pressure relieving mattress has been developed along with multilayered functional bed cover to reduce the magnitude, direction and or duration of pressure and temperature, thereby avoiding excessive tissue distortion on vulnerable parts of the body. The interface pressure and temperature between body and mattress are measured and analyzed using the parameters, such as deformation index and pressure gradient. The pressure relieving mattress developed reduces the interface pressure by $30-60 \%$ and reduces the pressure by about $30 \mathrm{o}$. Hence, the new mattress developed along with the cover reduces the chance for pressure ulcer formation and improves the comfort of the patients. In yet another interesting research, a study of indexes characterizing thermal comfort of garments have been outlined and a new so-called wet comfort index of sport dresses and underwear at real conditions of their use have been presented. The maximum value 1 indicates the best thermophysiological comfort level in wet state. It is found that for best sport dresses consisting of special polyester and polypropylene surface grooved fibres, the wet comfort index does not exceed 0.2 . This surprisingly low level demonstrates the importance of testing of thermal comfort properties of fabrics in wet state by means of special instruments.

Keywords: Thermal comfort; cold weather; hot weather; Comfort index; Insulation; Sports dresses

\section{Introduction}

Operational conditions in the Arctic open-pit mines are dependent on weather conditions with low temperatures, and long periods of the darkness in wintertime. The cold ambient conditions harm physical and mental performance [1] and increase hazards of occupational accidents directly by cooling the workers and indirectly e.g. by slippery surfaces [2]. Human body reacts to exposure to cold by decreasing circulation in body parts like skin, arms and legs to prevent heat loss, which further facilitates the cooling. Especially when Hands and feet are exposed to cooling as their own heat production is less and therefore their heat balance depends almost totally on the heat transported by blood circulation. Cooling of hands results at first sensation of cold and if cooling continues, manual performance will be reduced and cause cold pain and even loss of sensations could occur $[3,4]$. Though feet react to cooling by the same way as hands, it takes longer to [5]. Achievement of optimum level of thermal comfort is the most important requirement of any type 
of clothing. Thermal comfort of clothing for a long duration can be achieved from thermal balance between body heat production and body thermal losses when the clothing or garment is worn. On an average, human body can produce heat based on the level of physical activity which ranges from $80 \mathrm{~W}$ even from sleeping and more than $1000 \mathrm{~W}$ during very active sports [6]. In many cases, the body activity is accompanied by sweating, which leads to wetting of the garment fabrics and hence changes in fabric heat and moisture transfer properties. However, these changes decrease the thermos physiological comfort level.

As moisture level increases, thermal insulation of most of the garments decreases and simultaneously the garment water vapor permeability decreases. All these lead to disruption of thermal balance of the body. Deserts cover nearly $7 \%$ of the land area of the earth's surface. In hot dry deserts and semi-deserts, the typical air temperature ranges between $35^{\circ} \mathrm{C}$ and $55^{\circ} \mathrm{C}$ and relative humidity of air remains less than $40 \%$; often becomes $4-10 \%$. Nearly, $6 \%$ of global population is living here. The heat flux of solar radiation during midday can become $750 \mathrm{~W} / \mathrm{m} 2$ or even more. The clothing used in these extreme climates is the best option to give sufficient protection from direct exposure to sun and provide thermo-physical comfort to the wearer who is generally exposed to dangerous intense solar radiation and high air temperature during the day. Though people in subtropical desert regions use special style of clothing, a scientific exploration of the various design factors of clothing for such application is not recorded often. Majority of hospitals in India are using hard mattresses, covered with a waterproof coated fabric, over which a simple single layered cotton bedspread is used, which makes the patient highly uncomfortable due to the strain and heat generated on the contact areas. When the pressure on any part of the body increases beyond $33 \mathrm{~mm}$ mercury level, blood circulation is arrested which leads to bedsore development. When attempting to fully understand the pressure-sore phenomenon. In addition to pressure, many other factors identified to contribute to the damage.

Studies have shown that various factors such as shear stress, impact loading of tissue, elevated temperature and humidity, age of the person, nutritional status, general health, activity level deformity, posture and postural change, body stature, and psychological deficits contribute to bed sore formation. Few causative factors in pressure ulcer development are pressure, temperature, shearing, friction, and moisture [7-14]. Human body has a typical core temperature of $37^{\circ} \mathrm{C}$, and the skin has a typical temperature of $33{ }^{\circ} \mathrm{C}-34{ }^{\circ} \mathrm{C}$ under normal condition [15]. As the tolerance of the thermo -physiological system of human body is narrow, care must be taken to maintain and retain thermo-physiological comfort by ensuring an optimum heat flow across the skin. An ordinary human being can be considered to be in a thermo-physiologically comfortable state when the average outward (or cooling) heat flux across his skin from body core to environment is around $90-120 \mathrm{~W} / \mathrm{m} 2$. This net heat flux is generated due to metabolic activity, environment condition along with the design and properties of the clothing.

Clothing comfort being subjective perception is a complex property. When any functional garment is designed, then thermal comfort as a part of total comfort plays a significant role. Many researchers focused on the prediction of total comfort or its parts by means of asset of measurable properties and characterizing it by using some parameters or indexes. During last decades several indexes were proposed for characterization of comfort or its part, e.g. thermal comfort, physiological comfort, etc. Generally, it is possible to divide the indexes into two main groups:

a. The indexes, based only on inherent properties of textile fabric and

b. The indexes, which also include the properties of environment.

Two indexes proposed by Hes can be included to the first group. The first index, called index of quality (IQ) describes protection and wear comfort of winter jackets. Their thermal resistance, water vapour permeability and minimum thermal comfort levels create this IQ index. The second index is more complex [16]. This chapter covers different attempts to measure the thermal comfort and innovative design concepts to achieve the same through clothing and other mechanisms.

\section{Evaluation of Thermal Comfort in Cold Climatic Zone}

According to Fanger [17], there are three requirements to fulfill for a person's whole-body thermal

\section{comfort:}

a. To balance the body heat,

b. The sweat rate within comfort limits and

c. Body temperature within comfort limits.

Absence of local thermal discomfort can be treated as fourth condition. People can ensure comfort and performance by altering behavioural thermoregulation, for example, moving to comfortable thermal conditions, adjusting clothing, increasing or decreasing physical activity, seeking shelter or adjusting posture. People those who work in open-pit mines in the Arctic region requires protection against cold and high-speed wind. Varying climatic conditions and nature of work create problems in the adjustment of the thermal insulation of clothing while working. Similarly, workload in mines fluctuates from rest to light and heavy work. Moreover, periods of heavy work may cause occasionally sweating and moisture accumulation into clothing. Gavhed et al. have identified that skin temperature and thermal sensation differs between continuous work and intermittent work, at equal energy expenditures [18]. The thermal protective properties of clothing are changed due to change in permeable properties of clothing during body movements at work, change in wind and moisture conditions. It is also recognized that 
material selection and clothing size plays an important role on the thermal protective properties and comfort of the clothing [19-23].

Many employers provide protective clothing for workers. Most of them provide only the outer clothing layer while few companies supply inner or middle clothing layers. Workers choose to use their own selection of winter garments below the outer clothing. People working in outdoor like open-pit miners, in the Arctic are exposed to the harsh weather conditions and manage well to protect themselves in the cold. There is not much information on how adequate the protective garments were and how adjustments could be made in the clothing depending upon duration and intensity of work, environmental and individual factors. Studies were initiated to find out, how Arctic openpit mine workers protect themselves against cold in real work environments, and the satisfactoriness of the selected protective clothing against the poor weather conditions. The study also evaluates the selection criteria of garment used in wintertime among open-pit miners [24]. The results indicated that the selection of winter clothing was based on working time outdoors or unheated sites, environmental conditions, sensitivity to cold and general health. But the clothing was not sufficient to prevent cooling when ambient temperatures is below $-10{ }^{\circ} \mathrm{C}$. The term "cool" can be unpleasant experience, but it will not cause harmful cooling or frostbites. If the person works in "cold" condition, the risk of harmful cooling may be experienced. The questionnaire study concluded that the "cold" thermal sensa?tions amplified when ambient temperature was lower than $-10^{\circ} \mathrm{C}$.

\section{Adequacy of Cold Protective Clothing}

Experiments with thermal manikin showed that five out of six unused workwear from four different open-pit reached the limit value ( 2 clo) of the standard for cold protective clothing [25]. Protective clothing used by Russian mine had only thermal vest, without any padding or lining (Figure 1). Only the selected garment combinations were considered to calculate the basic thermal insulation as per the standard ISO 992019.The basic thermal insulation value does not include boundary air layer and thus it is expected to correspond with real clothing insulation value. The mean values of the Icl were 1.22 clo $(0.186 \mathrm{~m} 2 \mathrm{~K} / \mathrm{W})$ in mild or wet cold (Ta from -5 to $+5{ }^{\circ} \mathrm{C}$ ) and 1.47 clo $(0.233$ $\mathrm{m} 2 \mathrm{~K} / \mathrm{W}$ ) in dry cold conditions ( Ta from -20 to $-10^{\circ} \mathrm{C}$ ). According to Insulation Required - index (IREQ)20) the calculated mean Icl is satisfactory for long term $(8 \mathrm{~h})$ moderate work $(150 \mathrm{~W} / \mathrm{m} 2)$ in mild cold conditions $\left(0^{\circ} \mathrm{C}\right)$, whereas the mean Icl selected for dry cold conditions $\left(-15^{\circ} \mathrm{C}\right)$ requires heavier work $(190 \mathrm{~W} / \mathrm{m} 2)$ to be performed to maintain thermal balance for long period (8h). Because the outdoor working periods were usually interrupted every $2-3 \mathrm{~h}$ by breaks either indoors or in vehicles, only peripheral skin temperatures (especially in fingers) decreased to the level causing complains.

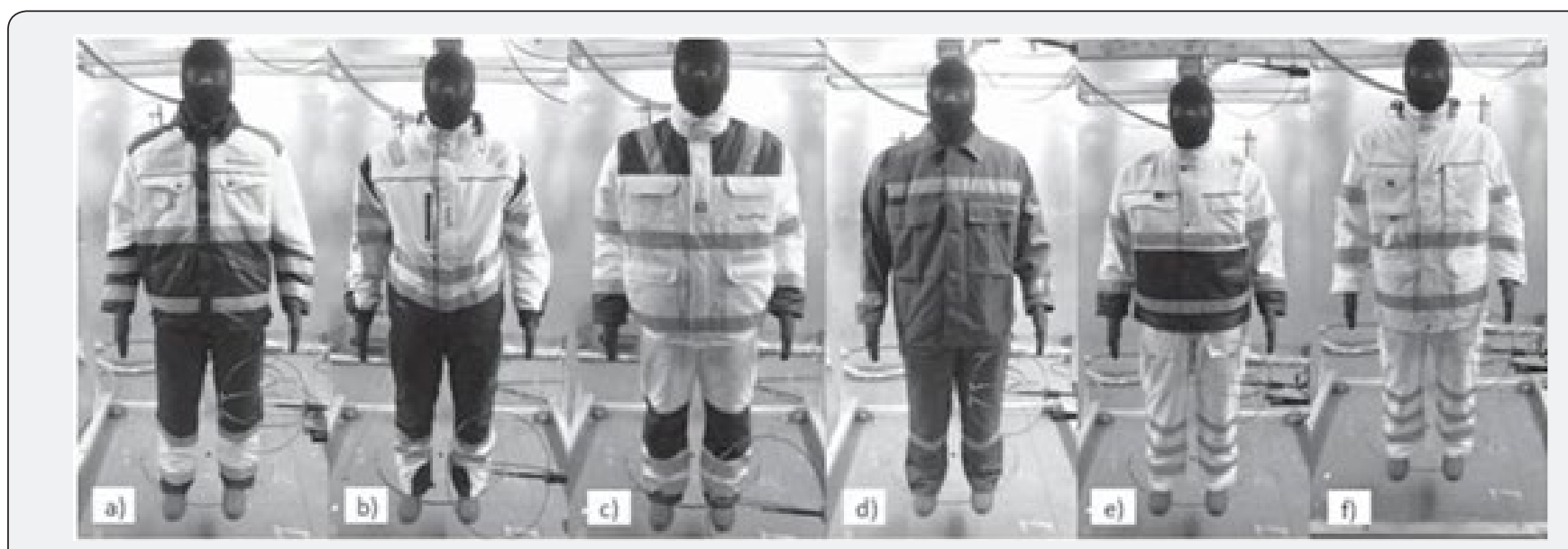

Figure 1: Clothing of open-pit mine workers from different countries.

\section{Selection criteria of Cold Protective Clothing}

Based the experiments, it is found that the basic thermal insulation varies between age, gender, weight or BMI. $8 \%$ of female respondents preferred warmer clothing in dry cold conditions. Also, it is noticed that workers with higher BMI (above 25) choose lower Icl. Working time outdoors or in unheated buildings or machines influenced on clothing selection. People who are exposed to longer time exposure use higher insulation clothing. This shows that workers can estimate the need for cold protection according to the duration of the work.
General health of the workers also influences clothing selection $(\mathrm{p}<0.05)$. In the mild condition's workers had lower Icl when they felt their general health being "very good" or "good" and higher when having "bad" feeling for their general health. In cold condition's, level of Icl was selected the opposite way. It is found that workers experiencing better general health adjusted their clothing more than workers with their general status worse. On the other hand, workers with reduced general health avoid to working long periods outdoors due to physically heavy tasks in the field. Whenever cold thermal sensation was perceived on the whole body, fingers or toes, the higher Icl of the clothing was 
selected $(\mathrm{p}<0.05)$. Similar correlation was found between the selected Icl and workers exposed to wind $(\mathrm{p}<0.01)$ and moisture $(p<0.01)$ at work. This refers that Arctic open-pit mine workers experience with cold thermal sensation help them to adjust and compensate it by additional clothing.

But, when the temperature goes below than $-10{ }^{\circ} \mathrm{C}$, even the higher Icl was not sufficient to prevent cooling of the whole body, fingers and hands. Higher Icl require thicker clothing that may hinder and limit the movements of hands and arms and thus decrease the physical performance at work and increase metabolic heat production. Clothing wetness due to sweating had also significant correlation with clothing selection $(\mathrm{p}<0.01)$ in mild and cold conditions. If clothing got often wet due to sweating, the higher Icl was selected. Based on the experience of open-pit miners who have the physical workload variation and moving between warm and cold ambient temperatures, the reason for sweating may be that workers are find difficult to adjust the clothing in changing situations at work. The use of other PPE may be one limiting factor preventing to add enough thermal protective clothing at work in the cold. The results show that when the higher Icl was selected, more problems in compatibility of different PPE was also experienced $(\mathrm{p}<0.01)$.

\section{Evaluation of Thermal Comfort of Sportswear and Underwear}

Comfort is a complex property and difficult to quantify it. When any new functional clothing is designed, thermal comfort plays a significant role. Hence, it is necessary to focus on the prediction of total comfort and its components by means of some indexes, measurable properties and parameters. During last decades several indexes were proposed for characterization of comfort or its part, e.g. thermal comfort, physiological comfort, etc. Generally, it is possible to divide the indexes into two main groups:

i. The indexes, based only on inherent properties of textile fabric, and

ii. The indexes, which also include the properties of environment.

Two indexes proposed by Hes, can be included to the first group. The first index, called index of quality (IQ) covers protection and wear comfort of winter jackets. Their thermal resistance, water vapour permeability and minimum thermal comfort levels formulate this IQ index. The second index is more complex. The proposal of comfort evaluation system (CES) consists of nine comfort parameters, where three parameters are related to thermal comfort, other three are related to sensorial comfort and the last three reflect the handle. Another complex solution was explained by Umbach [26]. He used thermo physiological comfort (WCT) as an indicator which consists of five properties, such as thermal resistance, moisture regulation index, sweat buffering, sweat transport and water retention. Together with sensorial comfort (WCS) having relation to the sensitivity of skin to mechanical and moisture irritations, the WCT creates the total wear comfort.

Physiological comfort index (IC) was presented by Militký and Matusiak. It involves four steps, and unacceptable and fully acceptable values of properties representing physiological comfort are determined. Matusiak also proposed thermal comfort index. For this index, thermal resistance, thermal absorbtivity, water vapor resistance and air permeability were used for prediction of thermo physiological comfort of the different textile materials. But it is very difficult to make decision on the ability of the studied fabric to provide thermal comfort under specific ambient conditions as the extreme levels of single fabric properties are not defined [27,28]. This drawback was corrected later by introduction of minimum and maximum levels of particular parameters into the formula and thus the relative thermal comfort index was proposed. Raj and Sreenivasan introduced two different indexes namely, the total wear comfort indexes for winter (TWCIw) and summer (TWCIs) wear [29]. Along with the characteristics relating into thermo physiological comfort (thermal and flow resistance and moisture transport rate) in these indexes, the total hand value (THV) representing tactile comfort was also incorporated. Thus, both indexes are contributing to characterize the overall quality of the apparel fabric. For evaluation of mechanical comfort of linen fabrics, Taiebet al proposed two indexes namely tactile mechanical comfort index (TMCI) and clothing mechanical comfort index (CMCI) [30]. According to them, higher values of both indexes denote the better mechanical comfort of a fabric.

Selection of the suitable mechanical properties is specified by the area of the fabric used. Thermal comfort equation developed by Fanger include six parameters, namely metabolic rate, cloth index, air velocity, mean radiant temperature, ambient air temperature and ambient water vapor pressure, which describes the state of the environment [31]. Based on the Fanger's parameters, Ma et al. presented prediction model of thermal comfort index using combination of neural network and genetic algorithm [32]. However, none of the presented indexes illustrate how the thermal comfort of clothes is changed when the fabric is moistened or sweated. Thermo physiological comfort of clothes, also called as thermal comfort of clothes, is fully characterized by their thermal resistance and water vapor permeability (or evaporation resistance) when the steadystate parameters are only considered. However, besides their steady-state properties, their dynamic (transient) properties are also important, like their thermal contact feeling, expressed in terms of thermal absorbtivity. Both the mentioned groups of the fabric properties are generally determined on dry fabrics. Both outerwear and particularly underwear fabrics (T-shirts, next-to- skin textiles, dresses) are frequently used in wet state, caused by the sweat condensation and absorption. As water vapour permeability and thermal resistance of textiles in dry and wet state differs, the simple index showing the changes in the 
thermal comfort based on the changes of mentioned properties in their dry and wet states is required.

The cooling flow resulting from the water evaporation from the wet fabric surface may not contribute to the skin cooling, and most of the cooling effect gets lost when the wet dress is in the direct contact with skin. Thermal resistance of the dresses which got wet during the training drops to $30-70 \%$ of the original (dry) values. Thermal absorbtivity of the studied dresses due to their wetting is increased by $30-190 \%$, where the last value indicates quite unpleasant and cold feeling. The results confirm that both effective relative water vapour Permeability (ERWVP) and thermal resistance of dresses, which got wet during the real sport activity, decrease substantively. This reduction is vary for dresses of various composition and structure. The best dresses exhibit, in wet state, the highest values of the mentioned ERVWP and thermal resistance (or Relative water Vapour permeability RWVPw and Rw).

To characterize the effect of moisture on thermophysiological comfort of under wear and sport dresses, a new so-called wet comfort index (WCI) is introduced, as shown below:

$$
W C I=\frac{E R W V P, R_{w}}{R W W P d, R_{d}}
$$

This index level ranges from 0 to 1 . WCI of the best underwear and sport dresses will approximate to the 1 value. The WCI level depend on fabric weight $(w)$, thickness $(t)$, fabric density (d) and fabric porosity (P) . The fabric density and porosity were calculated from the fabric square weight (g.m-2), fabric thickness (m) and fibre density (kg.m-3). The investigated properties and WCI is found to be independent. It implies that the fabric structure and fibre physical properties (such as hydrophobicity, capillary forces and moisture absorbtivity) play most important role in changes of thermo physiological comfort of fabrics caused by sweating. The results show that values of WCI for specified samples lie in the range from 0.05 (100\% cotton) to 0.2 (PA 56\%
/ PP $39 \%$ / EL 5\%). It indicates that after sweating the thermal comfort is changed noticeably, 5 times for the best material and 20 times for the worst material. It is apparent that the use of this index to characterize thermal comfort of sport dresses and underwear in wet state can be very helpful for the dress or underwear users [33]

\section{Innovative Design Concept for Comfort in Hot Weather}

The body generally loses heat due to pure heat convection transfer. This occurs due to sweat evaporation associated with free convection when air temperature is lower than the skin temperature or due to forced convection, when a human walk with common velocity $(3-4 \mathrm{~km} / \mathrm{h})$, which is around $1 \mathrm{~m} / \mathrm{s}$. The radiation loss from the body is largely managed by the incident scattered radiation from surrounding and the net balance depends on the temperature of the surrounding. However, the body is heated up primarily due to the metabolic heat generated inside. The convective heat transfer from atmosphere to skin when air temperature is higher than skin and radiation incident on skin, particularly direct radiation from hot sources such as Sun. Now, Clothing can act as an engineered system which could balance the heat towards the direction necessary so as to maintain a comfortable heat flow as mentioned above [34-39]. A lot of research work has been done in determining the role of various design parameters of clothing on the thermal comfort and protection provided by clothing ensemble. For example, the effects of pore distribution, air gaps and reflective layers have been studied experimentally using thermal Manikins. A number of empirical models for clothing comfort have been proposed as well. Only a few of them have discussed the role of radiation and hot climate on the overall heat-mass transfer through clothing. Shkolnik et al studied the effect of different dress styles and colors on the net heat transferred through the clothing to skin surface under real conditions in a desert [40]. They reported that both white and black robes used by Arabic tribes (Bedouins) give almost same net heat transfer from outside to skin in a standing upright condition.

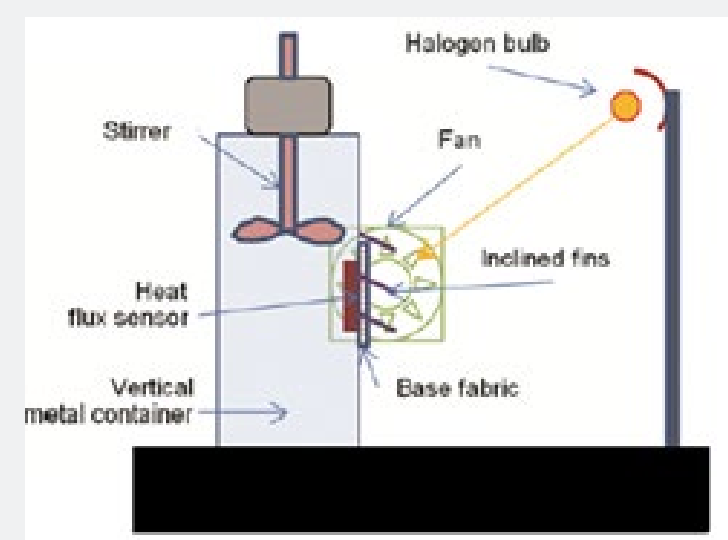

Figure 2: Experimental setup to measure heatflux. 
According to their study, these robes were better insulators than the army uniform or a semi-nude condition. They ascribed this due to either a bellows action or a chimney effect. Lotens developed a generic model for heat and mass transfer in clothing and showed that the model framework could be used to analyze the problem when the environment is hot and dry [41]. In another study, the possible role of the chimney effect in the narrow long gap between the outer fabric and the body in case of the Bedouin robes was studied [42]. However, the design of the dress for such hot-dry climates has not been discussed in terms of optimization or improvement over the existing solutions. It is generally assumed that the existing design has been optimized naturally during the long history of its use. Across the world, it can be seen that people use head gear which can provide large shadows over the body to protect it from the exposure to direct sunlight from very long time ago [43]. For example, Mexican 'Sombrero', or the Vietnamese 'Nónlá' or the Assamese 'Jaapi' all have a distinctive common feature, such as a large diameter of its span which extends far from the borders of the head Typically such head gears are used by farmers, fishermen or people who have to work for long periods under the hot Sun. The role of such shades over human skin under solar radiation has been investigated analytically and the results were examined experimentally. A novel device has been set-up which acts as a physical simulator of human skin and a high-power halogen bulb is used to simulate source of equivalent solar radiation [44] (Figure 2).

Direct measurement of heat flux at the simulated skin surface is done at various angles of the incident radiation. Small rectangular thin strips or fins of various opaque materials are used close to the simulated skin to generate small shadow on the sensor area. A mathematical analysis of the set-up is done to relate the heat-flow with the various adjustable parameters. Studies on effects of those parameters on heat flow at skin surface were carried out. The findings indicate that such thin inclined fins on the clothing can effectively improve the comfort under hot and dry outdoor conditions. This study, therefore, offers a new design concept to engineer the clothing surface to reduce heat load under dry hot radiation and the mathematical model forms a basic framework for analytical modelling the heat-mass transfer in such systems. Three different fabrics were used to prepare the fins and they were tried at different angles of inclination over the base fabric. The higher heat fluxes are noticed at the angles which provide more shadow area over the base material. It also showed that the fin material itself may have important influence on the cooling heat flow. The black polyester which is thicker and denser shows slightly better cooling flux in nearly all cases than the cotton fabrics. The color of the fabric used in the fins, on the other hand, does not show consistent influence on the cooling heat flux. A simple analytical model using fundamental equations of convection and radiation is able to describe the experimental situation. Therefore, such model can be further used to optimize the design for a desired heat flow.
It is also proved that the introduction of the fins significantly reduces the heat load on the skin surface.

As everybody experiences, the shades are much more comfortable than under direct sunlight in hot climates. The model, therefore, is also applicable to most kinds of inclined shades such as large hats ('Sombrero') or umbrella etc. The wedge-shaped air between the fins and the base material is very important as it gives the opportunity for evaporative cooling under forced convection. It must be mentioned here that the larger reserve of cooling flow $(\sim 300 \mathrm{~W} / \mathrm{m} 2)$ is necessary under the present set-up as the heat flux obtained from the halogen bulb used here is less by about $300 \mathrm{~W} / \mathrm{m} 2$ than the real solar radiation encountered in desert regions [45]. But the present study does not consider the other degree of freedom for attaching the fins, viz. the angle of the line connecting the fin with the base with respect to the horizontal line. Such inclination may help free convection as well as a component of the flow under the fins can then move effectively upwards. Therefore, the model may be improved to study this possibility. The air temperature in real desert may be even higher than skin temperature and the effectiveness of the fins in such condition needs to be evaluated experimentally as well as by the analytical model. The practical implementation of his effect is another step for future.

\section{Improvement in Heat and Mass transfer between Human Body and Hospital Mattress}

Bedsores are created at the places, where the weight of the person's body presses the skin against the firm surface of the bed. Pressure of less than 25\% (the pressure of a normal mattress) can cause bedsores. Complete muscle necrosis was observed at $100 \mathrm{mmHg}$ for $6 \mathrm{~h}$, the pressures of $70 \mathrm{mmHg}$ for $2 \mathrm{~h}$ results in pathological changes within the muscle and the lower pressure of $35 \mathrm{mmHg}$ for $4 \mathrm{~h}$ results in no change [46]. The metabolic heat generated by the body must be transferred through the bed linen. Otherwise, it leads to an increase in interface temperature between the body and the mattress. Elevated body temperature raises the metabolic activity of tissues by $10 \%$ for every $1{ }^{\circ} \mathrm{C}$ of temperature increase. Experiments with animal studies show that pressure induced tissue injury accelerate when the body temperature increases. For a bed ridden patient, shearing and friction can occur when they are dragged or slides across the bed sheets. Shearing and friction causes the skin to stretch and blood vessels to kink, which can weaken blood circulation in the skin. The wetness from perspiration, urine or faeces can make the skin too soft and easily get injured by pressure. Research studies record that around $11 \%$ of the hospitalized population and $20 \%$ of nursing home residents at any given time suffer from prevalence of pressure ulcer. For patients taking treatments in nursing homes, the incidence of pressure sores ranges from $7 \%$ to $35 \%$, which increases mortality rate four time higher. About $40-85 \%$ of spinal cord injured patients suffer from pressure ulcer in some centers. Maintaining healthy skin and avoiding 
breakdown are the major preventive measures practiced from past days [47-49].

Attempts to reduce pressure on a bony prominence is based on two principles viz.

i. Area in contact with the support surface can be increased,

ii. Contact can be temporarily removed or shifted to other areas.

In the first case, immersion and envelopment are the phenomena that produce reduction under pressure at a bony areas. In the second case, the change in areas of contact over time is the therapeutic consideration. If support surfaces mould around the body to maximize contact, it will effectively redistribute the patient's weight as uniformly as possible. According to Pascal's law, the weight of the body floating in a fluid system is evenly distributed over the entire surface. If the pressure is increasingly distributed over more body surface area, the intensity of pressure decreases over all body areas. Support surfaces also apply the principle of deformation which explains that they must be capable of deforming enough to permit prominent areas of the body to submerge into the support. The surfaces also must have the property to transmit pressure forces from one body area to another. An attempt has been made to develop a pressure relieving mattress with air circulation device and a multilayered bed cover sheet which is engineered for the required elongation, breathability and moisture management properties, so that it supplements the performance of the mattress which will overcome the problems faced by the patients and fulfil the basic comfort requirements of an immobile patient. The performance of the pressure relieving mattress and the cover material developed was analyzed by measuring the interface pressure, temperature, pressure gradient and deformation index. The cover material coated with phase changing material was examined using a scanning electron microscope and a differential scanning calorimetry.

\section{DSC Analysis of Microencapsulated PCM}

Effective thermoregulation of the patient's body is ensured by designing the cover material so as to absorb the heat developed in the interface between the body and the multilayered mattress by coating microencapsulated phase-changing material on the knitted fabric cover. DSC test results showed that the PCM coated knitted fabric can absorb heat in the body temperature range. Up to a temperature around $26^{\circ} \mathrm{C}$, the heat flow value is stable. It is noted the peak in the graph becomes wider when comparing microencapsulated n-octadecane with normal n-octadecane PCM. The phase transition of microencapsulated PCM occurs between (endothermic peak) $26^{\circ} \mathrm{C}$ and $40{ }^{\circ} \mathrm{C}$. This phenomenon indicates that the melting peak temperatures of the microcapsules are higher than that of normal n-octadecane, which may be attributed to low thermal conductivity of the shell materials [50]. In the same way, cooling (exothermic peak) appears from $36^{\circ} \mathrm{C}$ to $25^{\circ} \mathrm{C}$. The onset temperature of both endothermic and exothermic peaks varies from the original DSC curves of n-octadecane because of the shell material. The thermal conductivity of the shell materials affects the heat transfer rate from the outside to the PCM inside the shells, which, in turn, increases the phase change temperatures (latent heat) of the microcapsules.

\section{Interface Temperature between Body and Mattress}

The interface temperature between body and mattress was measured using the temperature measuring instrument developed. The LM35 sensor series are precision integratedcircuit temperature true sensor whose output voltage is linearly proportional to the Celsius temperature. When a patient lies for a long duration on the bed, unbearable heat is generated in the contact areas. This excessive heat creates restlessness in patients. The increase in temperature is measured on the patient body while lying on normal hospital bed and on the mattress developed. The room temperature was $31^{\circ} \mathrm{C}$ and the initial body temperature was $32.5^{\circ} \mathrm{C}$. Temperature is also measured with and without air circulation system. The result shows that there is a considerable reduction in the raise in temperature when compared to the normal hospital bed. The pressure reducing mattress with air circulation system reduces the heat generated in between the body and the top surface of the mattress. The air circulation device pumps air in through one nozzle and the air is sucked out through the other nozzle. Air leaks out through the small drill holes and ensures mild air circulation throughout the mattress, which reduces the heat generated by the body. The presence of dead air acts as thermal insulator and causes raise in temperature, whereas moving air assists in conducting the heat away through the circulated air. Hence, the mattress developed reduces the interface temperature and confirms the efficiency of the mattress in ensuring comfort to the patient.

\section{Interface Pressure between Body and Mattress}

One method of evaluating the weight of the body being transferred to the mattress surface is through the use of interface pressure (IP) measurements with pressure sensors. IP is a measure of the sum of forces being transmitted between the body and the mattress over the area of the pressure sensor. The pressure exerted on the body parts due to its own weight is measured using a Kikhume pressure sensor. When the pressure on any part of the body increases beyond 33mm mercury level, blood circulation is arrested which leads to bed sore development. To avoid excessive pressure, the area of contact of the body with the bed has to be increased. An increase in the contact area between any two objects will result in lowering peak pressure. This objective is achieved by developing a super soft polyurethane bed with hollow fibre filled mattress. The larger area of contact by the soft bed is also complemented by using knitted fabric in the top layer. The knitted fabric ensures good elongation, confirmation to body contour and reduced shear on the body. The interface pressure developed between body and 
mattress is measured for people of different weight range for both standard hospital mattress and newly developed pressure reducing mattress.

From the interface pressure measurement on the hospital mattress and the novel mattress developed, it can be observed that pressure developed on the body in hospital mattress is more than $33 \mathrm{~mm} \mathrm{Hg}$ in certain areas of the body, like head, midback, hip, buttocks and heel. As the body weight increases, the interface pressure also increases proportionately. The interface pressure is reduced drastically in the case of novel mattress. The reduction in pressure ranges from $30 \%$ to $66 \%$. This reduction in pressure is due to the highly soft nature of the hollow fibre filled part of the mattress which deforms to fit the shape of the body, thereby increasing the area of contact between the body and the mattress, leading to pressure distribution to more area. The terminologies used to explain these phenomena are 'Immersion' and 'Envelopment'. Immersion allows pressure concentrated beneath a bone to spread over the surrounding tissue. By increasing immersion, the potential for pressure reduction increases as the body weight is shifted to areas around other bony prominences. Envelopment describes a support surface ability to deform around irregularities on the surface, without causing a substantial increase in pressure. Due to higher envelopment and immersion of the soft mattress, body weight is distributed to more area and the interface pressure is reduced to a great extent.

\section{Measurement of Deformation Index}

Unevenly distributed weight rather than peak interface pressure is the main causative factor for pressure development. This concept is also supported by the experience of sea divers, who do not suffer from tissue damage because the higher hydrostatic pressure is applied evenly all over the body. Therefore, use of an index for pressure differentials or tissue deformation across the skin contact area may be a better guideline for support surface selection, particularly as this criterion is related to patient's comfort. The deformation index can be estimated by comparing peak to average pressure, as shown below:

\section{Deformation index $=\frac{\text { Peak pressure }- \text { Average pressure }}{\text { Average pressure }}$}

Total pressure is the sum of pressure measured on the eleven contact points of the body parts, and the average pressure is calculated by dividing the total pressure by the number of contact points; the peak pressure is found to be the maximum pressure measured among the eleven points. These parameters are calculated for the hospital mattress and the pressure relieving mattress developed separately for all the body weight ranges and then the deformation index is calculated and compared. Lower deformation index value implies that the strain on the body is minimum whereas, higher deformation index shows more strain on the body parts. The deviation of peak pressure from average pressure for the hospital mattress is high and the deformation index is around 1.6 which shows that the peak pressure is 2-3 times more than that of average pressure. However, in the pressure relieving mattress developed, the deformation index ranges from 0.95 to 1.28 which is much lower than that of the hospital mattress. From the reduction in the deformation index, it can be ascertained that the strain on the body and skin is reduced considerably in the mattress developed. The mattress developed gives an appreciable reduction of $23-33 \%$ in the deformation index.

\section{Measurement of Pressure Gradient}

Pressure gradient measurement records the difference in the pressure over a distance (generally over a short distance of less than one inch) from one part of the support surface to another. However, in general, pressure gradient represents a continuum of values over the distance measured. If the pressure across a surface is plotted, the pressure gradient would be the slope of the curve. The pressure gradient curve also indicates the amount of shear force experienced by the skin. Vertical gradients between applied pressures over closest areas of soft tissue shows increase in the shearing force, which damages the skin tissues. In Hospital mattress, pressure gradient is more than $10 \mathrm{mmHg}$ which causes more shear force on the skin. In specially designed novel mattress, the change in pressure is brought down to very gradual with the difference ranging from $1 \mathrm{mmHg}$ to $3 \mathrm{mmHg}$. The immersion created in the pressure relieving mattress and the knitted cover fabric leads to a gradual reduction in pressure and hence the shear force on the skin is reduced.

\section{Conclusion}

Human body is exposed to various external environmental conditions in winter and summer. Thermal comfort depends on combinations of clothing, climate, and physical activity. As Comfort is purely subjective property and varies across the people around the world, Lot of research work has been done to successfully achieve thermo physiological comfort for people working in extreme cold and hot environment. Engineered protective clothing can help people to maintain a comfortable heat balance between the body and external conditions. Right choice of clothing materials, innovative garment designs, technical modifications from innerwear to hospital mattress are recent contributions to achieve thermal comfort. A challenging part of measurement of thermo physiological comfort also reached to its greatest level by the use of novel laboratory instruments and analytical models.

\section{References}

1. Pilcher JJ, Nadler E, Busch C (2002) Effects of hot and cold temperature exposure on performance: a meta-analytic review. Ergonomics 45(10): 682-698.

2. Anttonen H, Pekkarinen A, Niskanen J (2009) Safety at work in cold environments and prevention of cold stress. Ind Health 47(3): 254261. 
3. Heus R, Daanen HAM, Havenith G (1995) Physiological criteria for functioning of hands in the cold: a review. Appl Ergon 26(1): 5-13.

4. Rissanen S, Hassi J, Juopperi K, Rintamäki H (2001) Effects of whole body cooling on sensory perception and manual performance in subjects with Raynaud's phenomenon. Comp Biochem Physiol A Mol Integr Physiol 128(4): 749-757.

5. Rintamäki H, Hassi J, Oksa J, Mäkinen T (1992) Rewarming of feet by lower and upper body exercise. Eur J Appl Physiol Occup Physiol 65(5): 427-432.

6. Matusiak M (2010) Thermal Comfort Index as a Method of Assessing the Thermal Comfort of Textile Materials. Fibres Text Eastern Eur 18 2(79): 45-50.

7. Brand PW, Kenedi RM (1976) Patient Monitoring. Bed Sore Biomechanics Macmillan Publishers, London pp. 183-184.

8. Hyman WA, Artigue RS (1976) Studies of soft tissue Metabolism. TIRR Rehabil Eng Rep pp. 26-59.

9. Fisher SV, Patterson RP (1983) Long-term pressure recordings under the ischial tuberosities of tetraplegics. Paraplegia 21: 99-106.

10. Hobson DA (1984) Is pressure the most important parameter? In: Decubitus Ulcers, Report of Symposium, Washington (DC): Paralyzed Veterans of America.

11. Kandhavadivu P, Rathinamoorthy R, Surjit R (2016) Enhancement of heat and mass transfer between human body and hospital mattress to reduce pressure ulcer formation. Indian Journal of Fibre \& Textile Research (IJFTR) 41(2): 200-206.

12. Zacharkow D, Charles C (1984) Wheelchair Posture and Pressure Sores. Charles C Thomas Publisher Ltd, Spring field, Illinois, US.

13. Garber SL \& Krouskop TA (1982) Body build and its relationship to pressure distribution in the seated wheelchair patient. Arch Phys Med Rehabil 63(1): 17-20.

14. Krouskop TA (1993) A Synthesis of the factors that contribute to pressure sore formation. Med Hypotheses 11(2): 255-267.

15. Kothari VK (2006) Thermo- Physiological comfort characteristics and blended yarn woven fabrics. Indian J Fibre Text Res 31(1): 178-186.

16. Hes L (2006) Proceedings $3^{\text {rd }}$ European Conference on Protective Clothing (CIOP-PIB, Warszawa Gdynia).

17. (2012) Sustainability of miner's well-being, health, work ability in the Barents region. A common challenge.

18. Gavhed DC, Nielsen R, Holmér I (1991)Thermoregulatory and subjective responses of clothed men in the cold during continuous and intermittent exercise. Eur J Appl Physiol Occup Physiol 63(1): 29-35.

19. Lu Y, Wang F, Wan X, Song G, Shi W, et al. (2015) Clothing resultant thermal insulation determined on a movable thermal manikin. Part I: effects of wind and body movement on total insulation. Int J Biometeorol 59(10):1475-1486.

20. Chen YS, Fan J, Zhang W (2003) Clothing thermal insulation during sweating. Text Res J 73(2): 152-157.

21. Havenith G, Nilsson HO (2004) Correction of clothing insulation for movement and wind effects, a meta-analysis. Eur J ApplPhysiol 92(6): 636-640.

22. Jussila K (2016) Clothing physiological properties of cold protective clothing and their effects on human experience. Doctoral thesis. Tampere University of Technology 1371: 1-89.

23. Chen YS, Fan J, Qian X, Zhang W (2004) Effect of garment fit on thermal insulation and evaporative resistance. Text Res J 74(8): 742-748.
24. Jussila K, Rissanen S, Aminoff A, Wahlström J, Vaktskjold A, et al. (2017) Thermal comfort sustained by cold protective clothing in Arctic openpit mining-a thermal manikin and questionnaire study. Industrial health 55(6): 537-548.

25. EN 342 (2004) Protective clothing-Ensembles for protection against cold. European Committee for Standardization pp 1-20.

26. Umbach KH (2004) Produktauszeichnung "Tragekomfort" am Point of Sale (POS). Melliand Textilber 85(10): 802-805

27. Militky J, Matusiak M (2006) $3^{\text {rd }}$ International Textile, Clothing \& Design Conference. In: Z Dragsevic (edn)., Proceedings.

28. Matusiak M, Sikorski K (2011) Relative Thermal Comfort Index as a Measure of the Usefulness of Fabrics for Winter Clothing Manufacturing. Fibres Text Eastern Eur 89(6): 94-100.

29. Raj S, Sreenivasan S (2009) Total Wear Comfort Index as an Objective Parameter for Characterization of Overall Wearability of Cotton Fabrics. J Eng Fibers Fabrics 4(4): 29-41.

30. Taieb AH, Msahli S, Sakli F (2010) A New Index for Evaluating the Mechanical Comfort of Linen Fabric. J Natural Fibres 7(4): 251-266.

31. Fanger PO (1974) Thermal Comfort. Arkady: Warsaw.

32. Ma B, Shu J, Wang Y (2011) Experimental Design and the GA-BP Prediction of Human Thermal Comfort Index. In: J KHao (eds.), Proceedings Seventh International Conference on Natural Computation, USA, pp. 771-775.

33. Bajzik V, Hes L, Dolezal I (2016) Changes in thermal comfort properties of sports wear and underwear due to their wetting. Indian Journal of Fibre\& Textile Research (IJFTR) 41(2): 161-166.

34. Ke Y, Havenith G, Zhang X, Li X, Li J (2013) Effects of wind and clothing apertures on local clothing ventilation rates and thermal insulation. Text Res J 84(9): 941-952.

35. Li J, Zhang Z, Wang Y, Guang Z (2013) Effects of inner and outer clothing combinations on firefighter ensembles' thermal- and moisture-related comfort levels. J Text Inst 104(5): 530-540.

36. Brode P, Kuklane K, Candes V, Den Hartog EA ,Griefahn B, et al. (2010) Heat Gain From Thermal Radiation Through Protective Clothing With Different Insulation, Reflectivity and Vapour Permeability. Int J Occu Saf Ergon 16(2): 231-244.

37. Den Hartog EA, Havenith G (2010) Analytical Study of the Heat Loss Attenuation by Clothing on Thermal Manikins Under Radiative Heat Loads. Int J Occu Saf Ergon 16(2): 245-261.

38. Holmer I (2006) Protective Clothing in Hot Environments. Industrial Health 44(3): 404-413.

39. Morrissey MP, Rossi RM (2013) The effect of wind, body movement and garment adjustments on the effective thermal resistance of clothing with low and high air permeability insulation. Text Res J 84(6): 583592.

40. Shkolnik A, Taylor CR, Finch V, Borut A (1980) why do Bedouins wear black robes in hot deserts? Nature 283(5745): 373-375.

41. Lotens WA (1993) Heat Transfer from Humans Wearing Clothing. Doctoral dissertation, Delft University of Technology, Delft , Netherlands.

42. Hes L, Bal, Boguslawska-Baczek M (2014) Fiber Society Spring 2014 Conference. Fibers for Progress (The Fiber Society) Proceedings.

43. Bal K, Hes L (2015) 15 ${ }^{\text {th }}$ AUTEX World Conference. Proceedings.

44. Joan E Sanders, Barry S, Goldstein, Daniel F Leotta (1995) Skin response to mechanical stress: Adaptation rather than breakdown -A review of the literature. J Rehabilitation Res Dev 32(3): 214. 
45. Bal K, Hes L, Bajzik V (2017) Analytical model to study a new design concept for providing comfort in hot arid climate. Indian Journal of Fibre\& Textile Research (IJFTR) 42(4): 379-385.

46. Sanders SL (1992) Pressure Ulcers, Part 1: Prevention Strategies. J Am Acad Nurse Prac 4(2): 63-70.

47. Allman RM, Laprade CA, Noel LB, Walker JM, Moorer CA (1986) Pressure sores among hospitalized patients. Ann Intern Med 105(3): 337-342.
48. Norton D, Mc Laren R, Exton-Smith AN (1975) An Investigation of Geriatric Nursing Problems in Hospital. In: $2^{\text {nd }}(\mathrm{edn}) ., \mathrm{Uk}, \mathrm{pp} .193$.

49. Richards JS (1981) Sci Dig 3: 22.

50.Zhang H, Wang X (2009) Fabrication and performances of microencapsulated phase change materials based on n-octadecane core and resorcinol-modified melamine-formaldehyde shell. Colloid Surf A: Physicochem Eng Asp 332(2-3): 129-138.

\section{Your next submission with Juniper Publishers} will reach you the below assets

- Quality Editorial service

- Swift Peer Review

- Reprints availability

- E-prints Service

- Manuscript Podcast for convenient understanding

- Global attainment for your research

- Manuscript accessibility in different formats ( Pdf, E-pub, Full Text, Audio)

- Unceasing customer service

Track the below URL for one-step submission https://juniperpublishers.com/online-submission.php 